\title{
Validação do Instrumento Team Factors Inventory em Empresas Brasileiras
}

\author{
Fernando Antonio Prado Gimenez \\ Edmundo Inácio Júnior
}

\section{RESUMO}

O objetivo do trabalho foi verificar a confiabilidade e validade da versão em português do instrumento denominado Team Factors Inventory/TFI. Este instrumento mede a propensão de uma equipe para a liderança criativa em sete fatores e consiste em um questionário de 37 perguntas dispostas em uma escala de Likert de cinco pontos. A metodologia abrangeu a revisão da literatura acerca da liderança criativa, a tradução do instrumento pelo método de backtranslation e a análise dos dados, utilizandose da estatística descritiva, testes de hipóteses, análises fatoriais e de variância, considerando as variáveis de controle sexo e empresas de base tecnológica e tradicional. A amostra foi de 114 respondentes, sendo 73 provenientes dos proprietários-gerentes de empresas residentes nas incubadoras tecnológicas do Estado do Paraná e 41 vindos de pequenas empresas prestadoras de serviço de Maringá. As análises estatísticas indicaram também que a versão em português do TFI obteve bons níveis de confiabilidade e validade. Isto significa que o TFI pode ser aplicado a um contexto cultural diverso do original, como o Brasil.

Palavras-chave: liderança criativa; empreendedorismo; fatores de equipes criativas; confiabilidade; validade.

\begin{abstract}
The aim of the paper was to test the validity and reliability of a Portuguese version of the Team Factors Inventory/TFI. This inventory measures the propensity of a team towards creative leadership and consists of a paper and pen measure with 37 items in a Likert-type scale. The method involved review of literature on creative leadership, backtranslation of the inventory, and data analysis through descriptive statistics, hypotheses testing, factor analysis, analysis of variance, using as control variables, sex, and type of enterprise. The sample consisted of 114 respondents, being 73 owner-managers of high-tech incubated firms and 41 owner-managers of service firms. Analyses indicated that the translated version into Portuguese of the inventory reached satisfactory levels of validity and reliability. This means that TFI may be applied in a cultural context different from its origin.
\end{abstract}

Key words: creative leadership; entrepreneurship; creative team factors; reliability; validity. 


\section{Consideraçṍes InICIAIS}

Ao se realizar uma pesquisa, uma das preocupações está em afastar, tanto quanto possível, os erros que possam levar a falsas interpretações dos dados (Craig \& Douglas, 2000). Das fontes de erros apontadas pelos autores, quatro delas englobam praticamente todo o possível universo de erros, sendo elas: o respondente, a situação, o avaliador e o instrumento (Cooper \& Schindler, 2002). $\mathrm{O}$ artigo tem como objetivo verificar a confiabilidade e validade da versão em português do instrumento denominado Team Factors Inventory - TFI (quarta fonte de erro). As três primeiras fontes de erros não serão tratadas neste artigo, uma vez que já foram objeto de investigação em outros trabalhos (Inácio Jr., 2002; Inácio Jr., Gimenez, \& Caetano, 2002).

Segundo os autores da área, três são os principais critérios para avaliação de um instrumento de medição: validade, confiabilidade e praticidade (Cooper \& Schindler, 2002). A validade diz respeito à extensão em que um teste mede aquilo que se desejaria medir, enquanto a confiabilidade está preocupada com questões de estabilidade e consistência. Ambas têm a ver com a exatidão e a precisão de um instrumento de medição. A praticidade está preocupada com vários fatores de economia, conveniência e interpretabilidade (Singleton, Jr \& Straits 1993). Estes três critérios serão discutidos de maneira a dar suporte às nossas análises e conclusões a respeito da adequação do TFI para mensurar o potencial de Liderança Criativa em equipes empreendedoras e inovadoras.

Esses temas - criatividade e empreendedorismo - possuem áreas de sobreposição, uma vez que o ato de empreender um negócio tem sido entendido como processo complexo e multifacetado, reconhecendo como variáveis influenciadoras as sociais (mobilidade social, cultura, sociedade), econômicas (incentivos de mercado, políticas públicas, capital de risco) e psicológicas (Carland \& Carland, 1991; Huefner, Hunt, \& Robinson, 1996; Kets de Vries, 1985). Dentre as características atribuídas ao empreendedor, as mais citadas são: lócus interno de controle, necessidade de realização, propensão ao risco, criatividade, visão, alta energia, postura estratégica e autoconfiança (Brockhaus, 1982; Carland, Hoy, Boulton, \& Carland, 1984; Hornaday, 1982; Vesper \& Gartner, 1997).

Neste artigo as definições mais adequadas ao estudo do fenômeno do empreendedorismo estão embasadas em trabalhos de Filion (1999a, 1999b) e Stewart Jr., Watson, Carland \& Carland (1999). Esses autores concordam em que o empreendedorismo é o resultado tangível ou intangível de uma pessoa com habilidades criativas, sendo uma complexa função de experiências de vida, 
oportunidades, capacidades individuais e que no seu exercício está inerente a variável risco, tanto na vida como na carreira do empreendedor. Colocado de outra forma, o empreendedor é alguém que, no processo de construção de uma visão, estabelece um negócio objetivando lucro e crescimento, apresentando comportamento inovador e adotando postura estratégica (Bruyat \& Julien, 2001).

A literatura sobre criatividade em estudos organizacionais tem focado principalmente a contribuição do indivíduo para a inovação e mudança técnica (Amabile, 1998). O modelo de Liderança Criativa, por seu turno, vem a contribuir com o preenchimento dessa lacuna, dirigindo a atenção para o comportamento do grupo e o gerenciamento da equipe. $\mathrm{O}$ modelo vem sendo desenvolvido recentemente no Reino Unido e não há relatos na literatura de sua aplicação em uma língua que não a inglesa. A presente pesquisa vem corroborar esse quadro, possibilitando a investigação da tendência de um dos comportamentos do empreendedor: a Liderança Criativa.

O TFI mede o potencial para a Liderança Criativa dentro de equipes inovadoras e empreendedoras e consiste em esforços recentes na construção de um novo modelo que permite explorar os processos que contribuem para o alto desempenho de equipes envolvidas com atividades inovadoras (Rickards \& Moger, 1999, 2000). Apesar de já haver trabalhos empíricos e análises estatísticas na versão original (Rickards, Chen, \& Moger, 2001), em inglês, esta é a primeira vez que é aplicado no Brasil. Assim, torna-se necessária a análise de validade e confiabilidade, pois "[...] o pesquisador que assume que uma escala desenvolvida para sua casa funcionará com igual eficácia no exterior está provavelmente procurando por problemas" (Knight, 1997, p. 213).

Nossa intenção também é verificar se o TFI é capaz de discriminar entre as respostas dos grupos de empreendedores, que diferem em suas características de negócio, isto é, se proprietários-gerentes de micro e pequenas empresas residentes nas incubadoras tecnológicas do estado do Paraná possuem maior tendência para a Liderança Criativa em relação à suas contrapartes, inseridos em ambiente mais maduro tecnologicamente e de menores oportunidades, atuando nos setores tradicionais de prestação de serviços da cidade de Maringá.

Neste trabalho denominamos proprietário-gerente aquelas pessoas que estão envolvidas com o gerenciamento rotineiro de empresa (Filion, 1999a, 1999b). Uma pessoa pode assumir papel empreendedor sem nunca se tornar proprietáriogerente de MPE's, como, por exemplo, aqueles que trabalham para outros. Por outro lado, os proprietários-gerentes de MPE's podem não ser considerados empreendedores, uma vez que, em geral, administram rotinas do dia-a-dia e não fazem nenhuma mudança significativa nos produtos ou serviços. 
Ainda, quando nos referimos a incubadoras tecnológicas, estamos tratando de empreendimentos que ofereçam espaço físico, por tempo limitado, para a instalação de empresas de base tecnológica, e que disponham de uma equipe técnica para dar suporte e consultoria a estas empresas, denominadas de residentes, ou seja, aquelas em processo de incubação, que utilizam a infraestrutura e os serviços oferecidos pela Incubadora, ocupando nela certo espaço físico, por tempo limitado.

Nosso pressuposto está baseado na idéia de que este tipo de negócio (de base tecnológica) pode ser ambiente apropriado para o florescer de comportamentos inovadores nas equipes e, como proposto em recentes estudos, para a manifestação da Liderança Criativa (Brush, Greene, \& Hart, 2002; Rickards, 1999).

Para tal, utilizou-se uma amostra de 115 respondentes provenientes desses dois grupos, sendo 73 das empresas de base tecnológica e 42 das empresas prestadoras de serviços. O artigo está estruturado em mais cinco seções adicionais, além das Considerações iniciais e Referências bibliográficas. A segunda seção, intitulada O modelo de Liderança Criativa, explica os principais antecedentes e pressupostos apresentados por seus autores (Rickards \& Moger, 2000). A seção três, O Instrumento, traz uma descrição do TFI. Procedimentos metodológicos são apresentados na quarta sessão, A amostra. A quinta seção, Resultados, propõe as análises acerca da validade e confiabilidade. Por fim, a sexta seção, Considerações Finais, aponta os principais resultados da adequação do TFI e da Liderança Criativa para o contexto brasileiro e faz algumas sugestões para trabalhos futuros.

\section{O Modelo de liderança Criativa}

Uma das recentes teorias sobre processos de criatividade em grupo é o modelo de Liderança Criativa (Rickards \& Moger, 2000). Para os autores, a Liderança Criativa é o processo fundamental que muda o comportamento criativo da equipe de inaceitável para aceitável e, posteriormente, para superior, mediante a introdução de estruturas benignas, enfatizando a cooperação (e não a coerção) e a mutualidade (situações que beneficiam o grupo e o líder ao mesmo tempo). Há também outros autores que têm salientado o papel do líder nos grupos e sua importância nos processos criativos. Entre eles, podem ser comentadas as idéias sobre trabalho colaborativo em equipes e o papel significativo do líder nesse contexto (Bennis \& Biederman, 1997) e o modelo de Liderança Conectiva (Lipman-Blumen, 2000) que, relaciona a atividade do empreendedor e as estratégias de liderança e criatividade que ele freqüentemente adota. 
A atenção dada por Rickards e Moger às estruturas benignas, associadas ao processo criativo em equipe, está em sintonia e acordo com outros trabalhos que mostram a importância de uma base compartilhada de entendimento, princípios e conhecimento (Alencar, 1995, 1998; Nonaka \& Takeuchi, 1997). Estruturas benignas devem ampliar as atividades individuais e grupais, sob as diversas contingências grupais (Rickards \& Moger, 2000). Porém Rickards e Moger acreditam que existem barreiras que impedem a inserção ou o desenvolvimento das estruturas benignas - que enfatizam cooperação e a mutualidade - no grupo e, conseqüentemente, fazem com que as equipes não sejam capazes de atingir o desempenho esperado, em termos criativos.

Esses autores utilizaram o modelo de desenvolvimento de equipes (Tuckman, 1965) para explicar como os fatores de equipes criativas podem influenciar a equipe em seu processo de constituição. Este modelo aborda as etapas que constituem o processo de formação de uma equipe, sendo: a) form (formação); b) storm (turbulência); c) norm (normatização); d) perform (desempenho). Uma quinta etapa foi adicionada posteriormente, e) adjourn (passagem ou finalização).

A etapa de formação consiste em uma fase de orientação e organização dos papéis entre os membros da equipe de trabalho; e continua até que conflitos interpessoais tenham sido expostos e identificados. Durante a etapa de turbulência há constante conflito de valores e objetivos entre cada membro. A finalização da etapa de turbulência indica que uma normatização no comportamento e nas relações entre os membros foi estabelecida, e permite então que os esforços da equipe de trabalho sejam totalmente direcionados para as tarefas e objetivos comuns da equipe - desempenho. A última etapa, finalização, é identificada durante o término da equipe de trabalho. Nesta etapa, os resultados obtidos pela equipe são avaliados pela organização e as conclusões podem significar a extinção da equipe ou, freqüentemente, uma possível adequação da equipe a novos objetivos, ou então que a equipe continuará seu trabalho (Rickards \& Moger, 2000).

Rickards e Moger (2000) modificaram este modelo, incluindo duas barreiras - uma fraca de comportamento e outra forte de desempenho - inerentes ao processo de formação e desempenho das equipes, que as impedem de constituírem-se, primeiramente e, posteriormente, de desempenharem resultados superiores. Segundo os autores, isto foi necessário porque o modelo não conseguia explicar duas questões "que mecanismos estão em jogo, quando uma equipe falha em atingir o desempenho esperado? e que mecanismos levam ao desempenho exemplar?" (Rickards \& Moger, 2000, p. 275). A Figura 1 ilustra o modelo. 
Figura 1: Modelo Revisado de Formação de Equipes de Tuckman

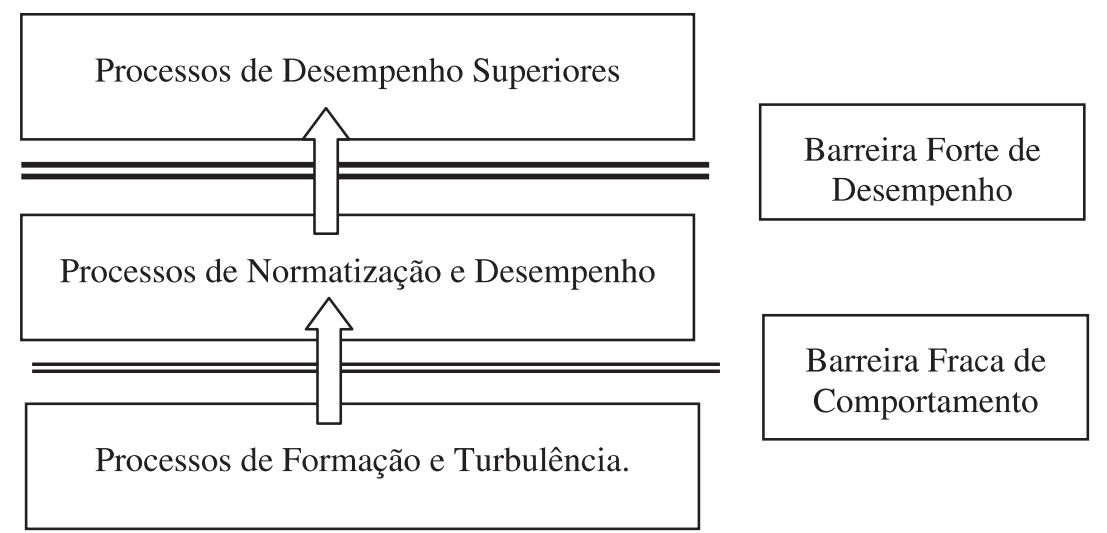

Fonte: Rickards e Moger (2000).

A primeira barreira é considerada uma barreira fraca de comportamento; mostrase presente em grupos que não conseguem superar a etapa de formação e turbulência. Superar esta barreira significa que as pessoas do grupo conseguiram estabelecer as relações pessoais entre si e o líder; é considerada uma barreira fraca por Rickards e Moger (2000), pois eles têm observado que a grande maioria de equipes criativas supera esta barreira. A segunda, considerada uma barreira forte de desempenho, indica a capacidade de criatividade e inovação que o grupo atingiu. Avaliar esse desempenho criativo dependerá da cultura organizacional presente, como observam os autores.

Para que se possa superar essas duas barreiras e, outras que, contingencialmente, aparecem nos grupos, Rickards e Moger (2000) reforçam a inserção das estruturas benignas, que são representadas pelos sete fatores de equipe criativas que distinguem equipes com elevado potencial para criatividade, sendo eles: plataforma de entendimento; visão compartilhada; clima; resiliência; idéias próprias; ativação em rede e aprendizado vindo da experiência. A maior ou menor presença dos fatores de equipes criativas faz com que as duas barreiras existentes que impedem a inserção ou o desenvolvimento das estruturas benignas no grupo e, conseqüentemente, fazem com que as equipes não sejam capazes de atingir o desempenho esperado em termos criativos, sejam quebradas. Rickards e Moger (2000) usam o termo barreira para indicar um impedimento estrutural ao desenvolvimento da criatividade. Os autores vêem as barreiras para o desenvolvimento de equipe tanto externamente, como pressões do ambiente, quanto internamente, como barreiras socialmente construídas. 


\section{O InSTRUMENTO}

A longa experiência que os autores possuem no estudo do modelo de solução de problemas - problem-solving model - e nos estudos da criatividade em grupos foram o ponto de partida para o desenvolvimento do TFI (Rickards, 1999; Rickards \& Moger, 1999). Inicialmente, para cada fator foi criada uma definição, isto é, uma sentença afirmativa. Depois, três a quatro sentenças afirmativas foram desenvolvidas para cada uma dessas definições. O conjunto de afirmativas foi então discutido com alunos de pós-graduação de diferentes origens e experiências, resultando na rejeição ou no refinamento de um pequeno número dessas afirmativas. Os autores decidiram selecionar três dessas afirmativas para cada um dos sete fatores, pois os autores acreditam que elas capturaram os aspectos essenciais contidos em cada definição. A Tabela 1 traz uma breve descrição dos sete fatores de equipes criativas, o código adotado para as análises, bem como as respectivas localizações das afirmativas no TFI.

\section{Tabela 1: Os Critérios que Compõe o TFI}

\begin{tabular}{|c|c|}
\hline $\begin{array}{c}\text { Critérios } \\
\text { (Código - No afirma }\end{array}$ & Principais características \\
\hline \multicolumn{2}{|c|}{ Sete fatores de equipes criativas } \\
\hline $\begin{array}{l}\text { Plataforma de } \\
\text { Entendimento } \\
(\mathrm{PE}-19,27 \text { e } 35)\end{array}$ & $\begin{array}{l}\text { Membros da equipe entendem e respeitam os pontos de vista uns dos outros, a equipe } \\
\text { compartilha conhecimento, crenças e convicções. Estes elementos incluem a } \\
\text { plataforma de entendimento da qual novas idéias se desenvolverão. }\end{array}$ \\
\hline $\begin{array}{l}\text { Visão } \\
\text { Compartilhada } \\
(\mathrm{VC}-6,7 \text { e } 13)\end{array}$ & $\begin{array}{l}\text { Membros da equipe compartilham senso de propósito e responsabilidades que } \\
\text { motivam e sustentam o progresso da equipe. Membros da equipe também levam } \\
\text { junto visões poderosas e significativas. }\end{array}$ \\
\hline $\begin{array}{l}\text { Clima } \\
(\mathrm{CL}-26,32 \text { e } 36)\end{array}$ & $\begin{array}{l}\text { Membros da equipe confiam uns nos outros e compartilham uma positiva e } \\
\text { acolhedora abordagem para estimular a criatividade no trabalho. }\end{array}$ \\
\hline $\begin{array}{l}\text { Idéias Próprias } \\
(\text { IP }-2,4 \text { e } 9)\end{array}$ & $\begin{array}{l}\text { As idéias a que se dá mais atenção são aquelas percebidas como abertas ao } \\
\text { comprometimento de toda a equipe. Uma equipe criativa cria e sustenta idéias novas } \\
\text { e valorosas de problemas relacionadas a tarefa. }\end{array}$ \\
\hline $\begin{array}{l}\text { Resiliência } \\
(\mathrm{RE}-16,20 \text { e } 34)\end{array}$ & Membros da equipe são flexíveis com suas frustrações e obstáculos. \\
\hline $\begin{array}{l}\text { Ativação em Rede } \\
(\mathrm{AR}-17,21 \text { e } 23)\end{array}$ & $\begin{array}{l}\text { Membros da equipe são bons em se comunicar com pessoas de fora da equipe, } \\
\text { trocando idéias e oferecendo apoio mútuo. }\end{array}$ \\
\hline $\begin{array}{l}\text { Aprendizado vindo } \\
\text { da Experiência } \\
(\mathrm{AE}-14,15 \text { e } 33)\end{array}$ & $\begin{array}{l}\text { Membros da equipe são orientados em direção do aprendizado vindo de suas próprias } \\
\text { experiências, permitindo assim crescer, mudar, adaptar e resolver problemas de } \\
\text { forma criativa. }\end{array}$ \\
\hline
\end{tabular}

Fonte: adaptado de Rickards et al. (2001, p. 245).

Adicionalmente, os autores incluíram mais quatro variáveis, contendo três itens cada, sendo elas três critérios de resultado: produtividade, criatividade e conhecimento e um critério de estilo de liderança (Transacional e Transformacional). $\mathrm{O}$ modelo de liderança transacional $\mathrm{x}$ transformacional devese a James MacGregor Burns, que é considerado um dos mais importantes 
contribuintes para as teorias de liderança que vieram após os anos 80 (Rickards, 1999, p. 123). Burns observou uma diferença fundamental de comportamento entre líderes que operavam em modelo próximo ao modelo econômico de trocas, o que ele chamou de Liderança Transacional, e líderes que mantinham comportamentos que transcendiam o egoísmo, que chamou de Liderança Transformacional. A Liderança Transacional está para o líder que procura identificar potenciais motivações em seus seguidores, procurando satisfazer as necessidades mais elevadas e engajar a pessoa completa de seus seguidores (Burns, 1979). Já a Liderança Transformacional "resulta em uma relação de estimulação e elevação mútua, que converte seguidores em líderes e pode converter líderes em agentes morais" (Burns, 1979, p.4). Sendo o tipo de liderança mais comum, relaciona-se ao líder que aborda seus seguidores com a intenção trocar uma coisa por outra, como cargos por votos, ou subsídios por contribuições de campanha (Burns, 1979, p. 4).

Dessa forma, o TFI - vide Anexo 1 da versão em português, utilizada na pesquisa - final resultou em 36 itens, embora possua 37 afirmativas. A primeira afirmativa é dummy e foi introduzida para focar a atenção do respondente. O propósito de inclusão desses critérios de estilo de liderança e resultado foi avaliar o impacto dos sete fatores de equipes criativas sobre estes. A intenção foi desenvolver um instrumento que pudesse ser usado por membros da equipes e por pesquisadores. $\mathrm{O}$ desenho do TFI foi baseado na premissa de se tentar estabelecer uma boa relação entre o maior nível de confiabilidade possível pelos longos questionários, e a maior aceitação possível pelos respondentes dos menos extensos. Um requisito importante que foi imposto era que o instrumento pudesse ser completado em não mais do que cinco minutos pela grande maioria de respondentes.

Uma escala de cinco pontos - escala de Likert - foi escolhida para medir todos os itens do TFI como segue: $5=$ concorda fortemente; $4=$ concorda; $3=$ neutro; $2=$ discorda; $1=$ discorda fortemente. Todas as questões foram expressas positivamente. $\mathrm{O}$ estilo das sentenças encoraja os respondentes a reportarem as características gerais que a equipe tem vivido. A maior ou menor presença dos sete fatores de equipes criativas coloca a equipe, segundo a escala do TFI, entre os valores de 0 a 5 pontos, contidos em três faixas: Team from hell $[0$ a 1,87); Standard team $[1,87$ a 3,10) e Dream team $[3,10$ a 5,00].

Como a utilização destes instrumentos é inédita no Brasil, foi necessária a tradução do inglês para o português. Para tal, adotou-se o método de backtranslation (Craig \& Douglas, 2000), que compreende a tradução do instrumento original - source - para o idioma alvo - target, e sua re-tradução para o idioma original, novamente. Após, compara-se os resultados e, caso necessário, se refaz o mesmo processo até que o instrumento resultante contenha 
o mesmo significado em todo seu contexto. Normalmente, recomenda-se utilizar para a tradução uma pessoa que tenha como língua mãe o idioma alvo e para a re-tradução uma pessoa que tenha como língua mãe o idioma original.

\section{A Amostra}

A amostra de respondentes caracterizou-se como de conveniência, suficientemente grande para eliminar dúvidas quanto a sua representatividade, tanto para os proprietários-gerentes das empresas de base tecnológica do Estado do Paraná, quanto aos proprietários-gerentes das empresas tradicionais do setor de serviços da cidade de Maringá-PR. Tal assertiva tem seus pressupostos no Teorema do Limite Central (Silver, 2000; Steverson, 1986) que assegura que para uma grande população a média amostral representa a média populacional, sendo que uma de amostra $n \geq 30$ já seria estatisticamente significativa, com nível de confiança de $95 \%$.

Contudo os autores tomaram dois cuidados na seleção do tamanho da amostra. A primeira diz respeito ao fato de que a população de empresas de base tecnológica pode ser considerada uma pequena população em relação às centenas de micro e pequenas empresas do setor de serviços. Assim, para se garantir a robustez das análises, não só do presente estudo - da validade e confiabilidade do instrumento - como também do aproveitamento dos dados para a análise dos resultados do TFI em si, utilizamos para determinação de uma amostra probabilística, a fórmula para população finita (pequena) com estimação da proporção, dada por:

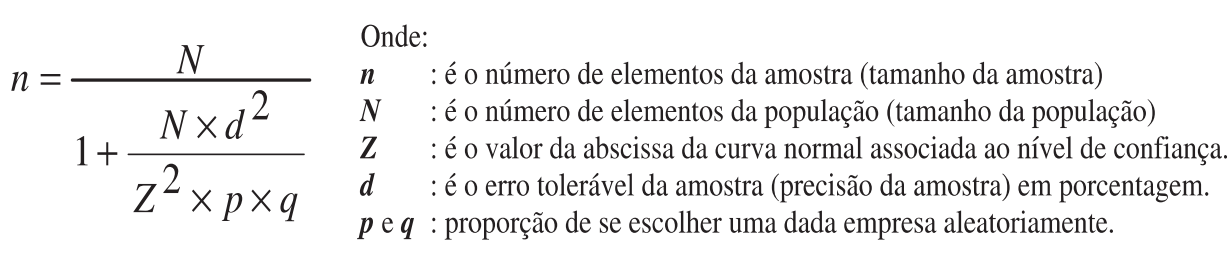

Então, com o universo de $N=55$ empresas, dados de 2000, para um nível de significância pré-fixado de 5\%, conforme afirmou Steverson (1986), para estudos nas áreas sociais, é comum utilizar-se, resultando um valor $\boldsymbol{Z}=1,96$, admitindo-se que a proporção é desconhecida e que, portanto, se utiliza $\boldsymbol{p}=\boldsymbol{q}=0,5$, pois que dá o maior tamanho possível de amostra; e, tomando-se $\boldsymbol{d}$ (erro amostral) de 0,10, admitindo-se que intervalos de $+/-10 \%$ de variação sobre a média das pontuações do TFI encontrada fornece clara definição da tendência adotada, o tamanho mínimo necessário seria de 35 empresas. Como resultado obtiveram-se 73 questionários 
respondidos, que englobaram 38 empresas diferentes de todas as oito incubadoras daquela época.

O segundo cuidado diz respeito às análises estatísticas de confiabilidade e validade. A literatura sugere que Análises Fatoriais - como as aqui empregadas devem ter tamanho amostral relativamente grande em comparação ao número de variáveis envolvidas. Há uma série de sugestões para a escolha desse tamanho amostral. Em geral, essas opções baseiam-se na experiência pessoal dos diversos autores que, em alguns casos, sugerem que o tamanho amostral deva ser da ordem de 5 a 20 vezes o número de variáveis envolvidas, não devendo ser utilizada amostra inferior a 50 observações, sendo que a análise seja feita, preferencialmente, com pelo menos 100 observações (Artes, 1998; Kline, 1994; Menezes, 1998). Assim, nossa amostra satisfaz as condições necessárias e os objetivos pretendidos. As informações sobre os dados demográficos da amostra podem ser vistas na Tabela 2 .

Tabela 2: Dados Demográficos da Amostra

\begin{tabular}{|c|c|c|c|c|c|c|c|c|}
\hline \multirow{3}{*}{ Critérios } & \multicolumn{8}{|c|}{ Empresas } \\
\hline & \multicolumn{2}{|c|}{ Base tecnológica } & \multicolumn{3}{|c|}{ Tradicional } & \multicolumn{3}{|c|}{ Total } \\
\hline & $\mathrm{n}$ & $(\%)$ & $\mathrm{N}$ & $(\%$ & & $\mathrm{N}$ & $(\%$ & \\
\hline$<20$ & 4 & 5,5 & 0 & & 0 & 4 & & 3,5 \\
\hline$[20,25)$ & 20 & 27,4 & 3 & & 1 & 23 & & 20,0 \\
\hline$[25,30)$ & 25 & 34,2 & 6 & 14 & & 31 & & 27,0 \\
\hline$[30,35)$ & 3 & 4,1 & 4 & & 5 & 7 & & 6,1 \\
\hline$[35,40)$ & 8 & 11,0 & 8 & 19 & & 16 & & 13,9 \\
\hline$[40,45)$ & 2 & 2,7 & 12 & 28 & & 14 & & 12,2 \\
\hline$\geq 45$ & 5 & 6,8 & 9 & 21 & & 14 & & 12,2 \\
\hline $\bar{N} / I^{*}$ & 6 & 8,2 & 0 & & 0 & 6 & & 5,2 \\
\hline Média & \multicolumn{2}{|c|}{27,9} & \multicolumn{3}{|c|}{38,3} & \multicolumn{3}{|c|}{31,9} \\
\hline Respondentes & 73 & 63,5 & 42 & 36 & & 115 & & 100,0 \\
\hline \multicolumn{9}{|l|}{ Sexo } \\
\hline Masculino & 56 & 76,7 & 32 & 76 & & 88 & & 76,5 \\
\hline Feminino & 17 & 23,3 & 10 & 23 & & 27 & & 23,5 \\
\hline \multicolumn{9}{|l|}{ Tipo de equipe } \\
\hline Team from hell & 0 & 0,0 & 0 & & 0 & 0 & & 0,0 \\
\hline Standart team & 3 & 4,1 & 6 & 14 & & 9 & & 7,8 \\
\hline Dream team & 70 & 95,9 & 36 & 85 & & 106 & & 92,2 \\
\hline Incubadora & Inc-01 & Inc-02 & Inc-03 & Inc-04 & Inc-05 & Inc-06 & Inc-07 & Inc-08 \\
\hline Número de empresas & 9 & 6 & 3 & 2 & 9 & 3 & 4 & 2 \\
\hline$(\%)$ & 12 & 8 & 4 & 3 & 12 & 4 & 5 & 3 \\
\hline Número de respondentes & 21 & 13 & 3 & 3 & 16 & 9 & 5 & 3 \\
\hline$(\%)$ & 29 & 18 & 4 & 4 & 22 & 12 & 7 & 4 \\
\hline Localização & Maringá & $\begin{array}{c}\text { Pato } \\
\text { Branco }\end{array}$ & Cascavel & Curitiba & Curitiba & Londrina & $\begin{array}{c}\text { São } \\
\text { Mateus } \\
\text { do Sul }\end{array}$ & $\begin{array}{l}\text { Foz de } \\
\text { Iguaçu }\end{array}$ \\
\hline
\end{tabular}

Notas: $* \mathrm{~N} / \mathrm{I}=$ não informado; $\mathrm{n}=115$. 
Dos 115 questionários, 50\% dos respondentes têm menos de 30 anos de idade, sendo a menor idade de 16 e a maior de 60 anos, resultando em uma média de 32 anos. Uma diferença significativa foi verificada entre a idade dos proprietários-gerentes das empresas de base tecnológica e as empresas do setor de serviços tradicionais, sendo a idade dos primeiros, em média, 10 anos inferior ao dos segundos. A quantidade de respondentes entre os grupos de análise - base tecnológica e tradicional - foi desproporcional, sendo constituído de $64 \%$ e $36 \%$, respectivamente. Esta pesquisa considerou micro e pequenas empresas com faixa de pessoal ocupado entre 10 e 50 pessoas. Com relação ao sexo, $76 \%$ dos respondentes são do sexo masculino e $24 \%$ do sexo feminino.

Com relação às micro e pequenas empresas residentes, obtiveram-se 73 questionários respondidos, englobando 38 empresas diferentes de todas as oito incubadoras do Paraná. A grande maioria das empresas (75\%) trabalha na área tecnológica, de agribusiness, produção de software comercial e de entretenimento, automação industrial e soluções para Internet. Em geral, as incubadoras são recentes, com menos de três anos de existência. A Tabela 2 traz as informações quanto ao número de empresas pesquisas por incubadoras e o número de respondentes por empresa bem como a localização das incubadoras.

\section{Resultados}

São discutidos, a seguir, os resultados da confiabilidade e validade do TFI de maneira a dar suporte às análises. Para tal, esta seção está estruturada em três subseções. A primeira contém a análise da validade, a segunda contém a análise da confiabilidade e a terceira contém análises adicionais, tendo como objetivo demonstrar que o instrumento utilizado na pesquisa constitui instrumento robusto de pesquisa, mesmo para culturas diferentes.

\section{Validade de Construção}

Duas das principais formas de se avaliar a validade são: validade interna e externa. Abordamos somente a validade interna dos instrumentos neste artigo, uma vez que já existem trabalhos que tratam sobre a validade externa do TFI (Inácio \& Gimenez, 2002). Com relação à validade interna, dois procedimentos existem: validade de conteúdo e de construção. A primeira envolve um componente conceitual e a segunda um componente operacional. A primeira refere-se à 
avaliação, por parte do investigador, isto é, se o instrumento reflete o fenômeno que intenta medir. Esse julgamento é subjetivo, não sendo possível avaliar esse aspecto com métodos estatísticos e, sim, por meio do exame da literatura e das teorias que subjazem no fenômeno estudado, sendo, portanto, dependente do contexto histórico (Menezes, 1998).

A segunda, por sua vez, envolve uma avaliação sistemática do instrumento, analisando a maneira pela qual os itens se correlacionam em seus devidos fatores. Nesta seção trataremos da validade de construção, por meio da análise fatorial ${ }^{(1)}$. Ela é uma análise multivariada que se aplica à busca de identificação de fatores em um conjunto de medidas realizadas (Pereira, 1999). Conforme a proposição teórica do TFI, este consiste em sete fatores de equipes criativas. Existem, na literatura, vários critérios que auxiliam na determinação do número de fatores que, invariavelmente, quando empregados em um mesmo conjunto de dados, conduz a resultados diferentes (Artes, 1998). Dentre eles pode-se citar o critério de Kaiser, critério da porcentagem da variância explicada, critério scree test e métodos inferênciais.

Rickards et al. (2001) utilizaram em sua pesquisa o método Kaiser; seu resultado mostra que o padrão que melhor representava a estrutura de correlação dos itens com seus fatores foi obtida, quando se utilizaram sete fatores. Aplicando esse mesmo critério de extração de fatores - método Kaiser - nossa pesquisa também apontou para uma quantidade de fatores - em nosso caso cinco fatores - menor do que a proposta na teoria. Isso pode ser verificado pelos valores dos Eigenvalue apresentados na Tabela 3. Somente os cinco primeiros fatores possuem valores maior que 1 , conforme dita esse critério. Porém decidimos apresentar e avaliar a análise fatorial com a extração de sete fatores, pois o objetivo foi verificar a adequação com relação à proposição teórica.

A análise fatorial mostrou que todas as questões obtiveram cargas fatoriais superiores a 0,30 , e a grande maioria próxima a 0,70 , significando boa validade interna do instrumento. Apesar de seis itens não obterem sua maior carga fatorial em seus respectivos fatores, todos eles produziram cargas fatoriais significantes $(=0,30)$. Os fatores PE, RE e CL necessitam ser analisados novamente, pois cada um de seus itens carregou em fatores diferentes, não indicando, assim, uma tendência. Entretanto os sete fatores estão cobertos por múltiplas questões. A análise fatorial do TFI também apresentou equilíbrio bom entre a quantidade de fatores e a porcentagem de explicação dos mesmos: porcentagem de variância acumulada que explica $71 \%$ do total. A literatura aponta para um poder de explicação próximo de $70 \%$. 
Tabela 3: Análise Fatorial do TFI

\begin{tabular}{|c|c|c|c|c|c|c|c|}
\hline Itens & Fator 1 & Fator 2 & Fator 3 & Fator 4 & Fator 5 & Fator 6 & Fator 7 \\
\hline \multicolumn{8}{|l|}{ Visão compartilhada } \\
\hline VC6 & $\mathbf{0 , 7 8}$ & 0,17 & 0,10 & 0,03 & 0,33 & $-0,04$ & $-0,02$ \\
\hline VC7 & 0,71 & 0,21 & 0,00 & $-0,02$ & 0,20 & 0,26 & 0,32 \\
\hline $\mathrm{VC} 13$ & 0,71 & 0,01 & 0,08 & 0,26 & $-0,02$ & 0,21 & 0,21 \\
\hline \multicolumn{8}{|l|}{ Plataforma de entendimento } \\
\hline PE19 & 0,55 & 0,07 & 0,31 & 0,10 & 0,05 & 0,08 & 0,52 \\
\hline PE27 & 0,24 & 0,15 & 0,09 & 0,17 & 0,10 & 0,11 & 0,74 \\
\hline PE35 & 0,16 & $\mathbf{0 , 8 0}$ & 0,14 & 0,07 & 0,14 & 0,13 & 0,23 \\
\hline \multicolumn{8}{|l|}{ Ativação em rede } \\
\hline AR17 & 0,12 & 0,10 & 0,87 & 0,14 & 0,10 & $-0,05$ & 0,10 \\
\hline AR21 & 0,29 & 0,21 & 0,41 & 0,13 & $-0,03$ & 0,63 & $-0,21$ \\
\hline AR23 & 0,01 & 0,02 & 0,81 & 0,06 & 0,18 & 0,29 & 0,12 \\
\hline \multicolumn{8}{|l|}{ Resiliência } \\
\hline RE16 & 0,10 & 0,30 & 0,19 & 0,80 & 0,00 & 0,03 & 0,14 \\
\hline RE20 & 0,38 & 0,20 & 0,36 & 0,30 & 0,14 & 0,04 & 0,44 \\
\hline RE34 & 0,15 & 0,67 & $-0,05$ & 0,50 & 0,06 & 0,11 & $-0,13$ \\
\hline \multicolumn{8}{|l|}{ Idéias próprias } \\
\hline IP2 & 0,00 & 0,34 & 0,12 & 0,08 & 0,57 & 0,32 & 0,21 \\
\hline IP4 & 0,28 & 0,28 & 0,12 & 0,04 & 0,78 & $-0,02$ & $-0,01$ \\
\hline IP9 & 0,15 & $-0,16$ & 0,20 & 0,14 & 0,70 & 0,26 & 0,25 \\
\hline \multicolumn{8}{|l|}{ Aprendizado vindo da experiência } \\
\hline AE14 & 0,28 & 0,09 & 0,03 & 0,28 & 0,23 & 0,62 & 0,16 \\
\hline AE15 & 0,05 & 0,22 & 0,03 & 0,02 & 0,18 & 0,64 & 0,46 \\
\hline AE33 & $-0,01$ & 0,42 & 0,23 & 0,33 & 0,18 & 0,50 & 0,15 \\
\hline \multicolumn{8}{|l|}{ Clima } \\
\hline CL26 & 0,18 & 0,15 & 0,26 & 0,32 & 0,34 & 0,10 & 0,55 \\
\hline CL32 & 0,06 & $-0,07$ & 0,11 & 0,68 & 0,24 & 0,35 & 0,23 \\
\hline CL36 & 0,27 & 0,55 & 0,12 & 0,11 & 0,13 & 0,26 & 0,37 \\
\hline Eigenvalue & 7,75 & 1,58 & 1,47 & 1,21 & 1,11 & 0,97 & 0,88 \\
\hline Porcentagem acumulada da Variância & 36,90 & 44,40 & 51,42 & 57,18 & 62,46 & 67,09 & 71,26 \\
\hline
\end{tabular}

Notas: $\mathrm{n}=113$. Método de rotação: Varimax raw. Método de extração: Principal components.

\section{Confiabilidade}

A consistência interna indica a extensão com que cada um dos itens do TFI estão relacionados uns com os outros (Hayes, 1994). Quanto maior o inter-relacionamento entre os itens, maior é a consistência interna. O conceito subjacente à consistência interna é que se um instrumento que é projetado para medir uma determinada característica, por exemplo, visão compartilhada no TFI, possuir mais de um item para tal característica é esperado que estes se relacionem uns com os outros (Hayes, 1994). Isto significa dizer que os indivíduos que respondem de uma maneira com relação a um item (afirmativa, neste caso) muito provavelmente responderão da mesma maneira com relação a outro item da mesma característica. Como exemplo, pode-se citar as afirmativas PE19 'Membros da equipe têm bom entendimento das crenças e pressupostos de cada um' e PE35 'Membros da equipe têm bom entendimento das necessidades pessoais de cada um' do TFI. 
Há diversos tipos de estatísticas usadas para estimar o grau de consistência interna, sendo os testes mais comuns o Split-half e o Alfa de Cronbach ${ }^{(2)}$ (Hayes, 1994; Cooper \& Schindler, 2002). O Split-half pode ser usado, quando o instrumento tem várias questões ou afirmativas similares a que o indivíduo possa responder (Cooper \& Schindler, 2002). Normalmente, os resultados são separados por itens ímpares e pares. Se o resultado da correlação entre as metades é alto, o instrumento é dito ter alta confiabilidade no sentido de consistência interna. Segundo Bruning e Kintz (citado por Carland, Carland, \& Hoy, 1992), os índices de correlação (split-half, Guttman, Alfa de Cronbach) produzem resultados válidos, se a correlação estatística for igual ou maior que 0,70 . A Tabela 4 traz os resultados do teste do Split-half do TFI.

\section{Tabela 4: Análise de Confiabilidade: Consistência Interna - Split-half do TFI}

\begin{tabular}{cccccc}
\hline \multicolumn{6}{c}{ Confiabilidade Split-half=0,91 Confiabilidade Guttman split-half $=0,91$} \\
\hline $\begin{array}{c}\text { Meta- } \\
\text { des }\end{array}$ & $\begin{array}{c}\text { No } \\
\text { itens }\end{array}$ & Média & D.P. $\begin{array}{c}\text { Alfa de } \\
\text { Cronbach }\end{array}$ & Questões \\
\hline $1^{\text {a }}$ & 11 & 3,91 & 0,27 & 0,84 & IP2, VC6, IP9, AE14, RE16, AR17, PE19, AR23, PE 27, CL32 e RE34 \\
$2^{\text {a }}$ & 10 & 3,87 & 0,28 & 0,85 & IP4, VC7, VC13, AE15, RE20, AR21, CL26, AE33, PE35 e CL36. \\
\hline
\end{tabular}

Como pode ser visto na Tabela 4, ambos os índices de correlação (split-half e Guttman) produziram valores superiores a 0,70 . A correlação entre as duas metades foi de 0,82 ; porém este valor está sendo influenciado pelo número desigual de questões entre as duas metades, porque o TFI possui 21 afirmativas no total. Cooper e Schindler (2002) também afirmam que um problema com este teste é que a maneira pela qual foram divididas as duas metades influencia na correlação. Isto porque talvez na separação das questões em ímpar e par possa ter deixado de um lado, por exemplo, todas as afirmativas que versaram sobre uma característica, sendo que na outra metade, provavelmente não seria possível então encontrar uma associação forte. De modo geral, os dados demonstram um índice de correlação estatisticamente significativo, indicando que o instrumento é consistente e possui uma estrutura de itens relacionada.

Como comentado anteriormente, este teste sofre grande influência pela forma em que foram divididas as duas metades. Assim, o índice mais utilizado é o Alfa de Cronbach, pois este assegura estimativa confiável, sem ter a necessidade de dividir os itens testados (Cooper \& Schindler, 2002). O índice varia entre 0 e 1. Uma confiabilidade de 0 sugeriria que a pontuação observada não está relacionada à verdadeira pontuação delineada, e uma confiabilidade de 1 indicaria que a pontuação observada está perfeitamente relacionada com a verdadeira pontuação delineada (Hayes, 1994). Para alguns autores, valores iguais ou superiores a 0,80 
são níveis aceitáveis de confiabilidade (Hayes, 1994), enquanto para outros valores iguais ou superiores a 0,70 já bastam (Carland et al., 1992). Contudo, como aponta Pereira $(1999$, p. 87) "será tarefa do pesquisador julgar se o nível alcançado é satisfatório ou não, pois não há um ponto ideal de corte que se possa atribuir para a concepção de qualquer indicador".

Como se pode observar na Tabela 5, tanto a média como a variância não indicaram nenhum item que pudesse estar contribuindo ou prejudicando o TFI. A correlação item e total indicou forte inter-relacionamento dos itens. Todos os valores ficaram entre 0,24 e 0,25. O alfa de Cronbach para cada item praticamente não teve alterações com relação ao alfa geral de 0,90 , o que significa excelente consistência interna. De fato, apesar de o TFI estar em seus primeiros passos no processo de validação e ainda ser pouco utilizado em âmbito internacional, ele conseguiu bons índices de validade e confiabilidade quanto os apresentados pela versão original pesquisada por Rickards et al. (2001). Naquele estudo o Alfa de Cronbach foi de 0,94.

Tabela 5: Análise de Confiabilidade: Consistência Interna - Alfa de Cronbach do TFI

\begin{tabular}{|c|c|c|c|c|c|c|c|c|c|}
\hline & Alfa de Cro & $\begin{array}{r}\text { Resum } \\
\text { nbach: } 0,9 \\
\end{array}$ & $\begin{array}{l}\text { para e } \\
1 \text { Alfa } P\end{array}$ & $\begin{array}{l}\text { cala: } \text { Média = } \\
\text { dronizado: } \mathbf{0} \text {, }\end{array}$ & $\begin{array}{l}90 \text { D. P. } \\
\text { / Média }\end{array}$ & $\begin{array}{l}=0,52 \text { Váli } \\
\text { corr. corrig }\end{array}$ & $\begin{array}{l}\text { dos n:111 } \\
\text { Entre iten }\end{array}$ & n e total & \\
\hline $\begin{array}{l}\text { Ques- } \\
\text { tões }\end{array}$ & $\begin{array}{l}\text { Média se } \\
\text { item é } \\
\text { removido }\end{array}$ & $\begin{array}{l}\text { Variância } \\
\text { se item é } \\
\text { removido }\end{array}$ & $\begin{array}{c}\text { Corr. } \\
\text { corrig. } \\
\text { entre } \\
\text { item e } \\
\text { total }\end{array}$ & $\begin{array}{l}\text { Alfa se item } \\
\text { é removido }\end{array}$ & $\begin{array}{l}\text { Ques- } \\
\text { tões }\end{array}$ & $\begin{array}{l}\text { Média se } \\
\text { item é } \\
\text { removido }\end{array}$ & $\begin{array}{l}\text { Variância } \\
\text { se item é } \\
\text { removido }\end{array}$ & $\begin{array}{c}\text { Corr. } \\
\text { corrig. } \\
\text { entre } \\
\text { item e } \\
\text { total }\end{array}$ & $\begin{array}{l}\text { Alfa se item } \\
\text { é removido }\end{array}$ \\
\hline IP2 & 3,69 & 0,25 & 0,56 & 0,90 & RE20 & 3,70 & 0,24 & 0,61 & 0,90 \\
\hline IP4 & 3,70 & 0,25 & 0,50 & 0,90 & AR21 & 3,71 & 0,25 & 0,48 & 0,91 \\
\hline VC6 & 3,71 & 0,25 & 0,47 & 0,91 & AR23 & 3,70 & 0,25 & 0,47 & 0,91 \\
\hline VC7 & 3,71 & 0,24 & 0,62 & 0,90 & CL26 & 3,69 & 0,24 & 0,64 & 0,90 \\
\hline IP9 & 3,70 & 0,25 & 0,52 & 0,90 & PE27 & 3,70 & 0,25 & 0,55 & 0,90 \\
\hline $\mathrm{VC} 13$ & 3,71 & 0,25 & 0,52 & 0,90 & CL32 & 3,70 & 0,25 & 0,45 & 0,91 \\
\hline AE14 & 3,71 & 0,25 & 0,59 & 0,90 & AE33 & 3,70 & 0,25 & 0,58 & 0,90 \\
\hline AE15 & 3,70 & 0,25 & 0,55 & 0,90 & RE34 & 3,72 & 0,25 & 0,44 & 0,91 \\
\hline RE16 & 3,70 & 0,25 & 0,52 & 0,90 & PE35 & 3,72 & 0,25 & 0,58 & 0,90 \\
\hline AR17 & 3,70 & 0,25 & 0,43 & 0,91 & CL36 & 3,71 & 0,24 & 0,65 & 0,90 \\
\hline PE19 & 3,72 & 0,25 & 0,59 & 0,90 & & & & & \\
\hline
\end{tabular}

\section{Análises Adicionais}

Outra forma de se aprofundar na análise da confiabilidade e validade da versão em português do TFI é verificando a possível associação entre a pontuação do TFI e as variáveis sexo e grupo de análise. Pesquisadores concordam em que há diferenças psicológicas e sociais entre homens e mulheres com relação à maneira de agir e pensar no processo inovativo e de empreender, mas não com relação às capacidades e potencial de iniciar um negócio (Carland \& Carland, 1991; Fleenor \& Taylor, 1994; Gartner \& Shane, 1995). Dessa forma, espera-se uma diferença 
não significativa entre as médias dos respondentes homens e mulheres. Se os resultados caminharem na direção esperada, isto poderia significar que a versão em português do TFI seria bom instrumento para a diferenciação do potencial empreendedor dos indivíduos. A Tabela 6 indica que a hipótese de nulidade foi aceita, concluindo que não há diferença estatisticamente significativa entre a média da pontuação do TFI entre homens e mulheres, no nível de 5\%.

Tabela 6: Média do TFI por Sexo

\begin{tabular}{l|c|c|c}
\hline \multicolumn{1}{c|}{ Sexo } & Média do TFI & D.P. & N \\
\hline Feminino & 3,95 & 0,54 & 27 \\
\hline Masculino & 3,88 & 0,52 & 88 \\
\hline
\end{tabular}

$p=0,5368$ (não significativo no nível de 5\%)

Por outro lado, o TFI poderia servir para discriminar entre os respondentes de empresas de base tecnológica e empresas prestadoras de serviços tradicionais. A hipótese é que os proprietários-gerentes das empresas de base tecnológica obtenham pontuação superior àqueles tradicionais. Para se testar tal hipótese, levou-se a cabo um teste ANOVA one-way para testar a hipótese de nulidade de que as médias dos grupos de análise não são diferentes. Como pode ser visto na Tabela 7, a hipótese de nulidade foi rejeitada, concluindo que há diferença estatisticamente significativa entre a média da pontuação do TFI entre empresas tecnológicas e tradicionais, no nível de 5\%.

Tabela 7: Resumo One-way Anova

\begin{tabular}{l|r|c|c|c|c|}
\hline Fonte da variação & d.f. & SS & MS & Fvalue & PValue \\
\hline Modelo TFI & 1 & 5,077410 & 5,077410 & 22,14469 & 0,00007 \\
\hline Residual Erro & 113 & 25,90903 & 0,229283 & & \\
\hline Total & 114 & 30,98644 & & & \\
\hline $\begin{array}{l}\text { Fator: grupo de análise } \\
\text { Dependente: pontuação do TFI }\end{array}$ \\
\hline
\end{tabular}

\section{Resumo}

\begin{tabular}{l|c|r|r|r}
\hline \multicolumn{1}{c|}{ Grupo } & Código & Contagem & \multicolumn{1}{c|}{ Média } & \multicolumn{1}{c}{ D.P. } \\
\hline Empresa de base tecnológica & TEC & 73 & 4,06 & 0,46 \\
\hline Empresa de serviços tradicionais & TRA & 42 & 3,62 & 0,51 \\
\hline
\end{tabular}

Uma palavra de cuidado na interpretação desses resultados deve ser mencionada. Mais de $70 \%$ dos respondentes das empresas de base tecnológica possuem formação superior, e tiveram contatos prévios com teorias e modelos sobre empreendedorismo. Este contato certamente aconteceu em ambiente 
favorável, desde que muitos dos cursos de graduação no Brasil têm enfatizado a necessidade de se reforçar o comportamento empreendedor e inovador. Além disso, o atual clima social no Brasil para o empreendedorismo tem sido encorajado por políticas governamentais deliberadas. Isto, provavelmente, influencia o potencial em direção a uma orientação empreendedora dos respondentes (Fiet, 2001a, 2001b).

\section{Considerações Finais}

Nossa intenção foi discutir a confiabilidade e validade da versão em português do Team Factors Inventory - TFI. Como discussões preliminares de estudos futuros, este artigo indicou que a versão traduzida provou ser útil para a mensuração do potencial de Liderança Criativa e, de maneira geral, alcançou bons níveis de validade e confiabilidade. Esta conclusão é importante, pois permite que haja à disposição da comunidade acadêmica brasileira um instrumento de mensuração de comportamento de liderança e empreendedor aplicável à realidade das empresas brasileiras.

Um potencial benefício de se ter um instrumento bem projetado e validado para se medir a orientação empreendedora no Brasil é que isto pode contribuir para políticas governamentais mais eficientes e eficazes em direção ao empreendedorismo. Este instrumento pode ser usado, por exemplo, como ferramenta adicional de análise dos possíveis empreendedores com seus respectivos planos de negócio pelas agências públicas e privadas, tais como as incubadoras de empresas de base tecnológica. Estas reportaram recentemente em suas pesquisas que o principal elemento usado para a seleção de candidatos a serem incubados é o seu perfil empreendedor (ANPROTEC, 2001).

Além disso, o TFI vem-se mostrando útil na auto-avaliação pela própria equipe. Com os resultados obtidos em cada um dos sete fatores de equipes criativas e com treinamento adicional, para que a equipe possa entender seus conceitos e pressupostos, ele torna-se ferramenta de gerenciamento da capacidade de Liderança Criativa e, por conseguinte, da capacidade de inovar e empreender.

Estudos futuros terão, em primeiro lugar, que retornar à análise da relação entre os itens do instrumento e seu modelo teórico. Isto é necessário porque, como mencionado anteriormente, seis dos vinte e um itens não se relacionaram com seus devidos fatores como deveriam. Em segundo lugar, alguns itens terão que ser revistos contra uma possível preferência cultural Brasileira, 
embora os resultados pareçam indicar uma validade universal para o instrumento e modelo que o originou. Os altos índices de consistência interna, superiores aos padrões minimamente aceitáveis, conforme apresentado, indicam que não há dificuldades de entendimento das idéias contidas no modelo em sua versão em português. Por fim, para estudos futuros, seria aconselhável verificar como a versão em português do TFI se comportaria com uma população maior e mais diversificada.

\section{Artigo recebido em 05.11.2004. Aprovado em 10.02.2005.}

\section{Notas}

${ }^{1}$ Para os leitores não habituados alguns conceitos são importantes de se ter em mente, sendo eles: Carga Fatorial (factor loading): é a medida de correlação entre a função derivada e as medidas originais. Pode ser interpretado como se faz com o coeficiente de correlação de Pearson; Autovalor (eigenvalue): é a medida de quanto da variância total das medidas realizadas pode ser explicada pelo fator. $\mathrm{O}$ autovalor avalia a contribuição do fator ao modelo construído pela AF; Matriz fatorial: é a matriz de correlação entre as variáveis e os fatores encontrados (Pereira, 1999, p. 123-124).

${ }^{2}$ Para os leitores não habituados alguns conceitos são importantes de se ter em mente, sendo eles: Média se o item é desprezado: é a média aritmética do índice, ou seja, do TFI sem aquele item. Quanto menor for o valor da média do item, maior será a contribuição do mesmo para o índice; Variância se o item é desprezado: é a variância entre as médias encontrada para o item. Quanto menor for a variância do item, maior será sua contribuição para a variância, o que é indesejável; Correlação corrigida entre item e total: representa o coeficiente de correlação de Person (r) entre o item específico e o índice total, depurado de sua própria contribuição; Alfa se o item é desprezado: evidencia o impacto que teria a retirada de cada item considerado sobre o desempenho do índice. A inexistência de grandes diferenças entre os itens sugere boa consistência interna para o índice, que poderia ser mantido na forma como se encontra, sem exclusão de qualquer item (Pereira, 1999, p. 87-88).

\section{Referencias Bibliográficas}

Alencar, E. M. L. S. D. (1995, novembro/ dezembro).

Desenvolvendo a criatividade nas organizações: o desafio da inovação. Revista de Administração de Empresas, 35(6), 6-11.
Alencar, E. M. L. S. D. (1998, abril/junho). Promovendo um ambiente favorável à criatividade nas organizações Revista de Administração de Empresas, 38(2), 18-25. 
Amabile, T. (1998, September/October). How to kill creativity. Harvard Business Review, 76(5), 77-87.

Associação Nacional de Entidades Promotoras de Empreendimentos de Tecnologia Avançadas - ANPROTEC (2001).

Panorama 2000. Recuperado em 8 abril, 2001, de http:// www.anprotec.org.br.

Artes, R. (1998, setembro/outubro).

Aspectos estatísticos da análise fatorial de escalas de avaliação. Revista de Psiquiatria Clínica, 25(5), 223-228.

Bennis, W. G., \&

Biederman, P. W. (1997).

Organizing genius: the secret of creative collaboration. Reading: Addison-Wesley Publishing Company.

Brockhaus, R. H. (1982).

The psychology of the entrepreneur. In C. A. S. Kent, L. Donald, \& K. H. Vesper (Eds.). Encyclopedia of entrepreneurship. Englewood Cliffs, NJ.: Prentice-Hall.

Brush, C. G.,

Greene, P. G., \&

Hart, M. M. (2002, janeiro/março).

Empeendedorismo e construção da base de recursos. Revista de Administração de Empresas, 42(1), 20-35.

Bruyat, C., \&

Julien, P. A. (2001, March).

Defining the field of research in entrepreneurship. Journal of Business Venturing, 16(2), 165-180.
Burns, J. M. (1979).

Leadership. New York: Harper \& Row.

Carland, J. W.,

Carland, J. A. C., \&

Hoy, F. S. (1992).

An entrepreneurship Index: an empirical validation. Proceedings of the Frontiers of Entrepreneurship Research, France. Recuperado em 10 novembro, 2001, de http://www.babson.edu/entrep/fer/ front_92.html.

Carland, J. W.,

Hoy, F.,

Boulton, W. R., \&

Carland, J. A. C. (1984, April).

Differentiating entrepreneurs from small business owners: a conceptualization. The Academy of Management Review, 9(2), 354-360.

Carland, J. W., \&

Carland, J. A. (1991, April/June).

An empirical investigation into the distinctions between male and female entrepreneurs and managers. International Small Business Journal, 9(3), 62-72.

Cooper, D. R., \&

Schindler, P. (2002).

Business research methods (8th ed.). New York: McGraw-Hill//rwin.

Craig, C. S., \&

Douglas, S. P. (2000)

International marketing research (3rd ed.). Englewood Cliffs, New Jersey: Prentice-Hall.

Fiet, J. O. (2001a, March).

The pedagogical side of entrepreneurship theory. Journal of Business Venturing, 16(2), 101-117. 
Fiet, J. O. (2001b, March).

The theoretical side of teaching entrepreneurship. Journal of Business Venturing, 16(1), 1-24.

Filion, L. J. (1999a, outubro/novembro). Diferenças entre sistemas gerenciais de empreendedores e operadores de pequenos negócios. Revista de Administração de Empresas, 39(4), 620.

Filion, L. J. (1999b, abril/junho).

Empreendedorismo: empreendedores e proprietários-gerentes de pequenos negócios. Revista de Administração, 34(2), 5-28.

Fleenor, J. W., \&

Taylor, S. (1994, Summer).

Construct validity of three self-report measures of creativity. Educational and Psychological Measurement, 54(2), 464-470.

Gartner, W. B., \&

Shane, S. (1995, July).

Measuring entrepreneurship over time. Journal of Business Venturing, 10(4), 283-301.

Hayes, B. E. (1994, February).

How to Measure empowerment. Quality Progress, 27(2), 41-48.

Hornaday, J. A. (1982).

Research about living entrepreneurs. In C. A. S. Kent, L. Donald, \& K. H. Vesper (Eds.). Encyclopedia of entrepreneurship. Englewood Cliffs, NJ: Prentice-Hall.
Huefner, J. C.,

Hunt, H. K., \&

Robinson, P. B. (1996, Autumn).

A comparison of four scales predicting entrepreneurship. Academy of Entrepreneurship Journal, 1(2), 56-80.

Inácio, E., Jr. (2002)

Empreendedorismo e liderança criativa: um estudo com os proprietários-gerentes de empresa incubadas no estado do Paraná. Dissertação de Mestrado, Universidade Estadual de Maringá, Maringá, PR, Brasil.

Inácio, E., Jr. \&

Gimenez, F. A. P. (2002).

Investigando o potencial empreendedor e de liderança criativa. Anais do Encontro Nacional dos Programas de Pós-Graduação em Administração, Salvador, BA, 26.

Inácio, E., Jr., Gimenez, F. A. P., \& Caetano, J. M. V. (2002).

Creative leadership and entrepreneurs: an empirical investigation on Brazilian ownermanager of enterprises in business incubators. Proceedings of the British Academy of Management Annual Conference, London, Inglaterra.

Kets de Vries, M. F. R. (1985, November/ December).

The dark side of entrepreneurship. Harvard Business Review, 63(6), 160167.

Kline, P. (1994).

An easy guide to factor analysis. London: Routledge. 
Knight, G. A. (1997, May).

Cross-cultural reliability and validity of a scale to measure firm entrepreneurial orientation. Journal of Business Venturing, 12(3), 213-225.

Lipman-Blumen, J. (2000).

Connective leadership: managing in a changing world. Oxford: Oxford University Press.

Menezes, P. R. (1998, setembro/outubro). Validade e confiabilidade das escalas de avaliação em psiquiatria. Revista de Psiquiatria Clínica, 25(5), 214216.

Nonaka, I., \&

Takeuchi, H. (1997).

Criação de conhecimento na empresa: como as empresas japonesas geram a dinâmica da inovação. Rio de Janeiro: Campus.

Pereira, J. C. R. (1999).

Análise de dados qualitativos: estratégias metodológicas para as ciências da saúde, humanas e sociais. (2nd ed.). São Paulo: Ed. UNESP.

Rickards, T.(1999).

Creativity and the management of change. Oxford: Blackwell.

Rickards, T., \&

Moger, S. (1999).

Handbook for creative team leaders. UK: Gower.

Rickards, T., \&

Moger, S. (2000, December).

Creative leadership processes in project team development: an alternative to Tuckman's stage model.
British Journal of Management, 11(4), 273-283.

Rickards, T.,

Chen M., \&

Moger S. (2001, September)

Development of a self-report instrument for exploring team factor, leadership and performance relationships. British Journal of Management, 12(3), 243-250

Silver, M. (2000).

Estatística para administração. São Paulo: Atlas.

Singleton, R. A., Jr., \&

Straits, B. C. (1993).

Approaches to social research (3th ed.). Oxford: Oxford University Press.

Steverson, W. J. (1986).

Estatística aplicada à administração. São Paulo: Harbra.

Stewart W. H., Jr.,

Watson, W. E.,

Carland, J. A. C., \&

Carland, J. W. (1999, March).

A proclivity for entrepreneurship: a comparison of entrepreneurs, small business owners, and corporate managers. Journal of Business Venturing, 14(2), 189-214.

Tuckman, B. W. (1965, June).

Developmental sequences in small groups. Psychological Bulletin, 63(6), 384-399.

Vesper, K. H., \&

Gartner, W. B (1997, September).

Measuring progress in entrepreneurship education. Journal of Business Venturing, 12(5), 403-421. 


\section{ANexo A: Versão em Portugues do TFI}

1) Com base em sua equipe de trabalho, responda cada item abaixo marcando em uma escala de 5 a 1 (5= concordada fortemente; $4=$ concordada; $3=$ neutro; $2=$ discorda; $1=$ discorda fortemente).

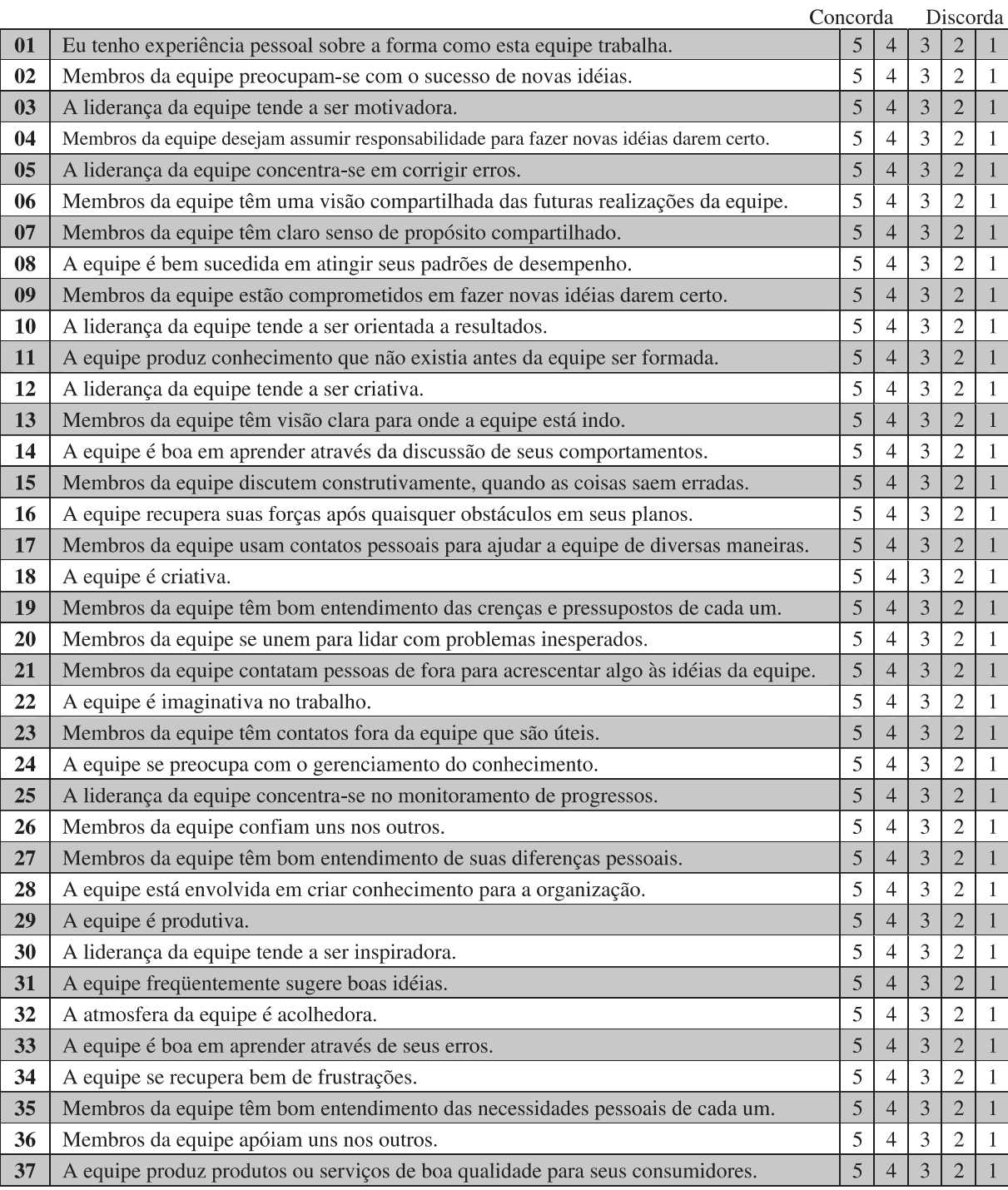

